\title{
ANALISA KEBUTUHAN RAK PENYIMPANAN BERKAS REKAM MEDIS RAWAT JALAN DI RUMAH SAKIT UMUM MADANI MEDAN
}

\author{
${ }^{1 .}$ Zulham Andi Ritonga; ${ }^{2 .}$ Nur Aisah Ritonga \\ 1. Dosen APIKES Imelda, Jalan Bilal Nomor 52 Medan; ${ }^{2}$ Alumni APIKES Imelda \\ E-mail: ${ }^{1 .}$ zulhamandi63@yahoo.com
}

\begin{abstract}
ABSTRAK
Rak penyimpanan merupakan salah satu peralatan rumah sakit yang berfungsi menyimpan dokumen rekam medis, dengan tersedianya rak penyimpanan dokumen rekam medis yang sesuai dengan kapasitas penyimpanan dokumen rekam medis maka tidak akan terjadi penumpukan dokumen di Lantai. Penelitian ini bertujuan untuk mengetahui perkiraan kebutuhan rak penyimpanan dokumen rekam medis rawat jalan di Rumah Sakit Umum Madani Medan Tahun 2018. Penelitian ini menggunakan metode deskriptif kuantitatif yaitu dengan memaparkan hasil penelitian apa adanya dan membandingkan dengan teori yang kemudian diambil kesimpulan. Waktu penelitian dilaksanakan pada bulan Oktober 2017-Januari 2018 di Rumah Sakit Umum Madani Medan. Populasi dan sampel yang digunakan adalah rak penyimpanan dan dokumen rekam medis rawat jalan. Instrumen yang digunakan dalam pengumpulan data antara lain dengan observasi dan wawancara. Hasil penelitian ini menunjukkan bahwa jumlah kunjungan pasien rawat jalan di Rumah Sakit Umum Madani Medan dari tahun 2014 - 2016 sebanyak 52.439. Jumlah rak penyimpanan rekam medis rawat jalan di Rumah Sakit Umum Madani Medan sebanyak 7 rak. Jika saat ini rumah sakit memiliki 7 rak file, maka rumah sakit perlu menyediakan 4 rak file lagi agar kebutuhan rak dapat tercukupi dan dapat menampung semua berkas rekam medis pasien secara sistematis dan tidak menyulitkan petugas dalam proses penyimpanan dan pencarian berkas rekam medis pasien.
\end{abstract}

Kata Kunci: Rawat Jalan, Rekam Medis, Rak Penyimpanan.

\section{PENDAHULUAN}

Ketersediaan rak penyimpanan berkas rekam medis di fasilitas pelayanan kesehatan merupakan hal yang sangat penting dalam menjaga keamanan dan menghindari kerusakan data pasien. Rak penyimpanan berada di dalam ruangan penyimpanan rekam medis rumah sakit. Kebutuhan akan rak penyimpanan berkas rekam medis rawat jalan harus sesuai dengan jumlah kunjungan pasien rawat jalan di rumah sakit.

Menurut Undang-Undang Nomor 44 tahun 2009, rumah sakit adalah institusi pelayanan kesehatan yang menyelenggarakan pelayanan kesehatan per orangan secara paripurna yang menyediakan pelayanan rawat inap, rawat jalan, dan gawat darurat. Seluruh pelayanan pasien rawat jalan yang dilakukan oleh petugas kesehatan di rumah sakit akan dicatat dan direkam yang disebut Rekam medis.

Menurut Huffman (1994), rekam medis adalah berkas yang menyatakan siapa, apa, dimana, mengapa, kapan dan bagaimana pelayanan yang diperoleh seorang pasien selama dirawat atau menjalani pengobatan. Rekam medis merupakan kumpulan fakta tentang riwayat dan penyakitnya, termasuk keadaan sakit, pengobatan saat ini dan saat lampau yang ditulis oleh para praktisi kesehatan dalam upaya mereka memberikan pelayanan kesehatan kepada pasien.

Sesuai permenkes (2008), rekam medis adalah berkas yang berisikan catatan dan dokumen tentang identitas pasien, pemeriksaan, pengobatan tindakan dan pelayanan lain yang telah diberikan kepada 
pasien. Menurut Hatta (2011), rekam medis merupakan berkas yang berisikan catatan dan dokumen tentang identitas pasien, pemeriksaan, pengobatan, tindakan, dan pelayanan lain yang telah diberikan kepada pasien.

Rak file merupakan tempat penyimpanan arsip atau dokumen rekam medis yang bertujuan untuk memudahkan penyimpanan dan pengambilan kembali dokumen rekam medis di ruang penyimpanan serta menjaga kerahasiaan dokumen rekam medis.

Oleh karena itu ruang penyimpanan menampung dokumen rekam medis, apabila rak penyimpanan melebihi daya tampung maka diperlukan perencanaan atau pengadaan rak penyimpanan kembali. Perencanaan atau pengadaan rak penyimpanan berdasarkan jumlah dokumen rekam medis yang disimpan, bentuk rak dan ukuran rak penyimpanan yang sesuai standar ergonomi yaitu rak penyimpanan dapat berbentuk rak roll o'pack serta memperhatikan luas suatu ruangan yang tersedia.

Berdasarkan survei awal yang dilakukan di RSU Madani Medan, ruang penyimpanan rekam medis terdapat di tempat yang terpisah, yaitu di lantai satu menyimpan berkas rekam medis pasien rawat jalan dan lantai empat menyimpan berkas rekam medis rawat inap. Tempat penyimpanan rekam medis rawat jalan maupun rawat inap masih kurang efektif dikarenakan jarak antara satu rak dengan rak lainnya terlalu berdekatan dan ruangannya terlalu sempit sehingga petugas sulit untuk melakukan pekerjaan dengan baik.

Penelitian Ahmadi (2011) di RSUD Dr. H. Moch. Ansari Saleh Banjarmasin, bulan Maret jumlah pasien baru rawat jalan sebanyak $29,23 \%$ dan pasien lama rawat jalan sebanyak 70,97\%. Ukuran rekam medis rawat jalan dengan panjang $30 \mathrm{~cm}$, lebarnya $25 \mathrm{~cm}$ dan tebalnya $0,5 \mathrm{~cm}$.

Berdasarkan hasil pengamatan (observasi) di tempat penyimpanan rekam medis rawat jalan jumlah sub rak rekam medis sebanyak 280 sub rak dan luas ruangan penyimpanan rekam medis mempunyai panjang 6 meter dan lebarnya 4 meter, jadi luas yang terdapat di tempat penyimpanan seluas $24 \mathrm{~m}^{2}$ dengan jumlah sebanyak 12 rak rawat jalan, adapun jarak antara dua buah rak untuk berlalu lalang berjarak $60 \mathrm{~cm}$.

Berdasarkan permasalahan tersebut penulis tertarik untuk melakukan penelitian dengan judul "Analisa Kebutuhan Rak Penyimpanan Berkas Rekam Medis Rawat Jalan di Rumah Sakit Umum Madani Medan Tahun 2018".

\section{Rumusan Masalah}

Berdasarkan latar belakang di atas, maka rumusan masalah dalam penelitian ini adalah

1. Bagaimana Kebutuhan rak renyimpanan berkas rekam medis di RSU Madani Medan Tahun 2018?

2. Bagaimana standar rak penyimpanan berkas rekam medis?

\section{Tujuan Penelitian}

Dari rumusan masalah di atas, adapun tujuan penelitian ini untuk mengetahui kebutuhan rak penyimpanan dokumen rekam medis rawat jalan di RSU Madani Medan Tahun 2018.

\section{Manfaat Penelitian}

1. Bagi rumah sakit

Sebagai perencanaan dan pengambilan keputusan tentang masalah yang dihadapi dalam penyimpanan berkas rekam medis, sehingga berguna untuk bahan perbaikan dan pengembangan sistem penyimpanan berkas rekam medis di Rumah Sakit Umum Madani Medan.

2. Bagi penulis

Menambah pengetahuan dan keterampilan tentang kebutuhan rak penyimpanan berkas rekam medis di rumah sakit.

3. Bagi peneliti lain

Hasil peneliti ini juga diharapkan dapat memberikan referensi bagi penelitian yang sejenis di masa akan datang. 


\section{METODE}

\section{Jenis Penelitian}

Penelitian ini merupakan penelitian deskriptif kuantitatif, yaitu penulis mengamati sumber penelitian untuk melihat langsung gambaran atau deskripsi tentang keadaan masalahnya secara objektif, kemudian menganalisa masalah tersebut dengan apa adanya (Natoatmodjo 2010). Dengan menganalisis kebutuhan rak penyimpanan rekam medis rawat jalan di Rumah Sakit Umum Madani Medan Tahun 2018.

\section{Waktu dan Tempat Penelitian}

Waktu penelitian dilaksanakan pada bulan Oktober 2017 s/d Januari 2018. Tempat penelitian dilaksanakan di bagian ruang penyimpanan rekam medis rawat jalan di Rumah Sakit Umum Madani Medan. Rumah Sakit Umum Madani Medan, terletak di jalan A.R. Hakim No. 168 , kelurahan suka ramai, kecamatan medan area, terdiri dari 4 (empat) lantai. Rumah sakit ini pada awalnya adalah klinik madani. Sejalan dengan kebutuhan kesehatan dan meningkatknya kepercayaan masyarakat, maka ditingkatkan statusnya menjadi Rumah Sakit Umum Madani.

\section{Populasi}

Populasi merupakan keseluruhan data yang diperlukan dalam suatu penelitian (Saryono, 2010). Populasi dalam penelitian ini adalah rak penyimpanan berkas rekam medis yang berjumlah 7 (tujuh) unit, seluruh kunjungan pasien dan berkas rekam medis pasien rawat jalan yang ada di Rumah Sakit Umum Madani Medan.

\section{Sampel}

Sampel sebagian dari jumlah karakteristik yang dimiliki populasi (Saryono, 2010). Dalam penelitian ini sampel yang digunakan adalah dokumen rekam medis rawat jalan di Rumah Sakit Umum Madani Medan.

Sampel pada penelitan ini adalah :

$$
\begin{aligned}
n & =\frac{\mathrm{N}}{1+\mathrm{N}\left(\mathrm{d}^{2}\right)} \\
\mathrm{N} & =\text { Besar populasi } \\
\mathrm{n} & =\text { Besar sampel }
\end{aligned}
$$

$\mathrm{d}=$ Tingkat kepercayaan atau ketetapan yang diinginkan $(0,1)$

$$
\begin{aligned}
n & =\frac{52439}{1+52439(0,01)} \\
& =99,8 \\
& =100 \text { berkas rekam medis }
\end{aligned}
$$

\section{Teknik Pengambilan Sampel}

Teknik sampling merupakan teknik pengambilan sampel sumber data dengan pertimbangan tertentu yang dibuat oleh peneliti sendiri berdasarkan sifat atau ciriciri populasi yang telah diketahui sebelumnya (Notoatmodjo, 2010). Rak dokumen rekam medis rawat jalan diambil secara accidental sampling, yaitu pengambilan sampel dilakukan dengan cara mengambil data yang kebetulan ada pada saat penelitian dilakukan. Sedangkan berkas rekam medis pasien diambil secara systematic sampling, yaitu suatu metode pengambilan sampel, dimana hanya unsur pertama saja dari sampel dipilih secara acak sedangkan unsur-unsur selanjutnya dipilih secara sistematis dengan rumus sebagai berikut:

$$
\begin{aligned}
\mathrm{k} & =\frac{\mathrm{N}}{\mathrm{n}} \\
& =\frac{52.439}{100} \\
& =524,39 \\
& =524
\end{aligned}
$$

Maka cara pengambilan sampel adalah berkas rekam medis yang terdapat pada urutan kelipatan 524 dimulai dari rak pertama kolom pertama.

\section{Variabel penelitian}

Variabel adalah ukuran atau ciri yang dimiliki oleh anggota-anggota suatu kelompok yang berbeda dengan yang dimiliki oleh kelompok lain (Saryono 2013). Adapun variabel-variabel yang akan diamati oleh peneliti adalah sebagai berilut :

1. Rata-rata kunjungan pasien

2. Rata-rata ketebalan berkas rekam medis

3. Jumlah rak penyimpanan berkas rekam medis

4. Ukuran rak penyimpanan berkas rekam medis

5. Penyusutan rekam medis 


\section{Defenisi Operasional}

Defenisi operasional adalah untuk mendefenisikan variabel secara operasional yang diamati untuk memudahkan pengumpulan data dan membatasi ruang lingkup operasional (Saryono, 2008).

\begin{tabular}{|c|c|c|c|c|c|}
\hline No & Variabel & Definisi Operasional & Cara & Alat ukur & $\begin{array}{l}\text { Skala } \\
\text { Ukur }\end{array}$ \\
\hline 1 & $\begin{array}{l}\text { Rata-rata kunjungan } \\
\text { pasien }\end{array}$ & $\begin{array}{l}\text { Jumlah pasien yang berobat } \\
\text { ke rumah sakit }\end{array}$ & Observasi & $\begin{array}{l}\text { Kalkulator } \\
\text { (alat hitung) }\end{array}$ & Ratio \\
\hline 2 & $\begin{array}{l}\text { Rata-rata ketebalan } \\
\text { berkas rekam medis }\end{array}$ & $\begin{array}{l}\text { Ukuran tebal berkas rekam } \\
\text { medis yang diukur secara } \\
\text { matematis }\end{array}$ & Observasi & Meteran & Ratio \\
\hline 3 & $\begin{array}{l}\text { Ukuran rak } \\
\text { penyimpanan }\end{array}$ & $\begin{array}{l}\text { Ukuran rak penyimpanan } \\
\text { berkas rekam medis rawat } \\
\text { jalan yang di rumah sakit } \\
\text { dengan menggunakan rumus } \\
\text { matematika }\end{array}$ & Observasi & Meteran & Ratio \\
\hline 4 & $\begin{array}{l}\text { Jumlah rak } \\
\text { penyimpanan }\end{array}$ & $\begin{array}{l}\text { Jumlah rak yang tersedia } \\
\text { untuk menampung berkas } \\
\text { rekam medis pasien }\end{array}$ & Observasi & Checklis & Ordinal \\
\hline 5 & $\begin{array}{l}\text { Penyusutan berkas } \\
\text { rekam medis }\end{array}$ & $\begin{array}{l}\text { Belum pernah melakukan } \\
\text { penyusutan }\end{array}$ & Observasi & Checklis & Ratio \\
\hline
\end{tabular}

\section{Instrumen Penelitian}

Instrumen penelitian adalah alat atau fasilitas yang digunakan oleh peneliti dalam mengumpulkan data agar pekerjaannya lebih mudah dan hasilnya lebih baik (cermat, lengkap dan sistematis) sehingga lebih mudah diolah (Saryono, 2013). Maka instrumen yang akan digunakan dalam penelitian di Rumah Sakit Umum Madani Medan adalah:

\section{Pedoman Observasi}

Observasi atau pengamatan adalah untuk menyajikan gambaran realistik perilaku atau kejadian, untuk menjawab pertanyaan, untuk membantu mengerti perilaku manusia, dan untuk evaluasi yaitu melakukan pengukuran terhadap aspek tertentu, melakukan umpan balik terhadap pengukuran tersebut (Saryono, 2013).

2. Pedoman Wawancara

Wawancara atau interview adalah proses memperoleh keterangan untuk tujuan penelitian dengan cara tanya jawab sambil bertatap muka antara pewawancara dengan orang yang diwawancarai (Saryono, 2013)

\section{Cara Pengumpulan Data} yaitu:

Adapun sumber data yang digunakan

1. Data primer

Data primer diperoleh langsung dari petugas rekam medis dari sumber observasi dan wawancara prediksi kebutuhan rak dokumen rekam medis rawat jalan.

2. Data sekunder

Data sekunder adalah data yang sudah ada yaitu kebijakan prosedur atau Standar Operasional Prosedur (SOP) di Rumah Sakit Umum Madani Medan.

\section{Teknik Pengolahan dan Analisis Data}

Teknik pengolahan data yang dilakukan yaitu:

1. Editing

Kegiatan yang dilakukan untuk meninjau atau mengoreksi kembali hasil observasi data yang telah dikumpulkan guna mengetahui kesalahan-kesalahan.

2. Tabulasi

Menyusun data dari hasil penelitian dalam bentuk tabel.

3. Penyajian data 
Suatu cara pengolahan data dengan cara menyajikan hasil dari pengumpulan data berupa teks.

Data dalam penelitian ini dianalisa secara deskriptif, adalah memaparkan hasil penelitian apa adanya dan membandingkan dengan teori yang kemudian diambil kesimpulan. Dalam penelitian ini, teknik pengolahan data secara analisis univariat yang dilakukan terhadap tiap variable dari hasil penelitian yang berujuan untuk menjelaskan setiap variabel penelitian. Adapun cara penyajian data dalam penelitian ini adalah penyajian dalam bentuk teks, yang mana penyajian data hasil penelitian dalam bentuk uraian kalimat.

\section{HASIL}

Rata-rata Jumlah Pasien Rawat Jalan

Kunjungan pasien baru rawat jalan pertahun dapat dilihat pada tebel berikut:

Tabel 1. Jumlah Kunjungan Pasien Rawat Jalan Per-Tahun Di RSU Madani Medan

\begin{tabular}{ccc}
\hline No & $\begin{array}{c}\text { Tahun } \\
\text { Kunjungan }\end{array}$ & $\begin{array}{c}\text { Jumlah Dokumen } \\
\text { Rekam Medis }\end{array}$ \\
\hline 1 & 2014 & 4.168 \\
\hline 2 & 2015 & 10.144 \\
\hline 3 & 2016 & 38.127 \\
\hline & Jumlah & 52.439 \\
\hline
\end{tabular}

Dari tabel kunjungan pasien rawat jalan pada tahun 2014 - 2016, maka diketahui jumlah kunjungan pasien rawat jalan yaitu sebanyak 52.439 orang.

\section{Ketebalan Berkas Rekam Medis Rawat Jalan}

Dari tabel ketebalan berkas rekam medis pasien baru rawat jalan tahun 2017 yang berjumlah 100 berkas rekam medis, maka didapatlah rata-rata ketebalan berkas rekam medis $0,4 \mathrm{~cm}$. Dengan perhitungan sebagai berikut:

Jumlah seluruh berkas rekam medis $=100$ berkas
Berkas rekam medis yang berukuran:

$2 \mathrm{~mm}=51$ berkas

$5 \mathrm{~mm}=26$ berkas

$7 \mathrm{~mm}=16$ berkas

$12 \mathrm{~mm}=4$ berkas

$16 \mathrm{~mm}=2$ berkas

Maka : $2 \mathrm{~mm} \times 51=102$

$5 \mathrm{~mm} \times 26=130$

$7 \mathrm{~mm} \times 16=112$

$12 \mathrm{~mm} \times 4=72$

$16 \mathrm{~mm} \times 2=\underline{32 \quad+}$

$448 \mathrm{~mm}$

$$
=44,8 \mathrm{~cm}
$$

Jadi ukuran ketebalan berkas yang berjumlah 100 berkas adalah $44,8 \mathrm{~cm}$.

Untuk mencari rata-rata ketebalan berkas rekam medis dengan menggunakan rumus sebagai berikut:

$x=\frac{\text { Jumlah Ketebalan Berkas Rekam Medis }(\mathrm{cm})}{\text { Jumlah Berkas Rekam Medis }}$

$=\underline{44,8}$

100

$=0,44$

$=0,4 \mathrm{~cm}$

Dari perhitungan di atas, sehingga didapat ketebalan berkas rekam medis pasien baru rawat jalan yang diambil menjadi sampel yaitu $0,4 \mathrm{~cm}$.

\section{Ukuran Rak Penyimpanan Berkas Rekam Medis}

Rak penyimpanan berkas rekam medis yang tersedia di ruang penyimpanan berkas rekam medis di RSU Madani Medan dengan jumlah keseluruhan rak 7 unit dengan ketentuan masing-masing rak sebagai berikut:

a. 2 (dua) rak terdiri dari 6 (enam) kolom dan 3 (tiga) baris dengan panjang 230 $\mathrm{cm}$ dan lebar $270 \mathrm{~cm}$.

b. 3 (tiga) rak terdiri dari 4 (empat) baris dan 6 (enam) kolom dengan panjang $280 \mathrm{~cm}$ dan lebar $263 \mathrm{~cm}$.

c. 2 (dua) rak terdiri dari 4 (empat) baris dan 7 (tujuh) kolom dengan panjang $265 \mathrm{~cm}$ dan lebar $295 \mathrm{~cm}$.

Dari pengukuran rak penyimpanan berkas rekam medis di RSU Madani Medan dapat dilihat pada tabel berikut: 
Tabel 2. Hasil Pengukuran Rak Penyimpanan Berkas Rekam Medis Di RSU Madani Medan Tahun 2017

\begin{tabular}{ccccccc}
\hline \multirow{2}{*}{ Rak } & \multicolumn{3}{c}{$\begin{array}{c}\text { Rak Penyimpanan } \\
\text { Rekam Medis }\end{array}$} & \multirow{2}{*}{$\begin{array}{c}\text { Lebar } \\
\text { Kolom }\end{array}$} & Jumlah Rak & $\begin{array}{c}\text { Jumlah Lebar } \\
\text { Keseluruhan Rak }\end{array}$ \\
\cline { 2 - 4 } & Kolom & Baris & Jumlah & & & $2916 \mathrm{~cm}$ \\
\hline A & 6 & 3 & 18 & $81 \mathrm{~cm}$ & 2 & $4464 \mathrm{~cm}$ \\
\hline B & 6 & 4 & 24 & $62 \mathrm{~cm}$ & 3 & $3584 \mathrm{~cm}$ \\
\hline C & 7 & 4 & 28 & $64 \mathrm{~cm}$ & 2 & $10964 \mathrm{~cm}$ \\
\hline Jumlah & 19 & 11 & 70 & $209 \mathrm{~cm}$ & 7 & \\
\hline
\end{tabular}

Berdasarkan hasil pengukuran yang dilakukan oleh penulis terhadap penyimpanan berkas rekam medis di Rumah Sakit Madani Medan yang telah dicantumkan pada tabel 4.2 di atas, maka didapat jumlah lebar keseluruhan adalah $\pm 10964 \mathrm{~cm}$, dengan rata-rata lebar rak 1566 $\mathrm{cm}$

\section{Kebutuhan Jumlah Rak}

Dengan terjawabnya jumlah rata-rata kunjungan pasien yang berobat ke rumah sakit tersebut dengan ukuran rata-rata ketebalan berkas rekam medis pasien rawat jalan dengan perhitungan sebagai berikut:

File Expansion $=$ rata-rata tebal DRM $\times 25$ $\%$

$$
\begin{aligned}
& =0,4 \times 25 \% \\
& =0,1
\end{aligned}
$$

$\mathrm{PP}$ dibutuhkan $=$ jumlah $\mathrm{DRM} \times$ (tebal $\mathrm{DRM}+$ hasil hitung expansion)

PP terasedia = jumlah sub rak $\times$ panjang sub rak

Kebutuhan rak $=\underline{\mathrm{PP} \text { dibutuhkan }}$ PP tersedia

Tabel 3. Prediksi Kebutuhan Rak Penyimpanan Tahun 2014 - 2016 Dengan File Expansion

\begin{tabular}{ccclll}
\hline No & Tahun & File Expansion & PP Dibutuhkan & PP Tersedia & Kebutuhan Rak \\
\hline \multirow{2}{*}{2014} & $0,4 \times 25 \%=0,1$ & $\begin{array}{l}4.168 \times \\
(0,4+0,1) \\
=2.084\end{array}$ & $\begin{array}{l}18 \times 81 \\
=1458\end{array}$ & $2084: 1458=2$ \\
\hline 2 & \multirow{2}{*}{2015} & $0,4 \times 25 \%=0,1$ & $\begin{array}{l}10.144 \times(0,4+0,1) \\
=5.072\end{array}$ & $\begin{array}{l}24 \times 62 \\
=1488\end{array}$ & $5072: 1488=4$ \\
\hline 3 & \multirow{2}{*}{2016} & $0,4 \times 25 \%=0,1$ & $\begin{array}{l}38.127 \times(0,4+0,1) \\
=19.063,5\end{array}$ & $\begin{array}{l}28 \times 64 \\
=1792\end{array}$ & $\begin{array}{l}19063,5: 1792= \\
11\end{array}$ \\
\hline
\end{tabular}

Jadi untuk prediksi kebutuhan rak periode tahun 2014-2016 dengan file expansion $25 \%$ adalah berjumlah 11 rak file, jika saat ini tersedia sejumlah 7 rak, maka sampai dengan tahun 2016 perlu menyediakan 4 rak file lagi agar pertambahan dokumen rekam medis bisa tersimpan kedalam rak, jumlah prediksi kebutuhan rak file tersebut tanpa memperhitungkan penyusutan karena sampai saat ini belum pernah dilakukan penyusutan.

\section{PEMBAHASAN}

\section{Rata-Rata Kunjungan Pasien}

Setiap hari pasien terus bertambah dan berkas rekam medisnya bertambah pula seiring dengan bertambahnya jumlah pasien setiap hari dan ketebalan berkas rekam medis di dalam rak penyimpanan akan bertambah pula. Berdasarkan hasil penelitian yang penulis lakukan di Rumah Sakit Umum Madani Medan bahwa rata-rata kunjungan pasien mulai dari tahun 2014-2016 yaitu berjumlah 52.439 orang. Dengan jumlah kunjungan pasien sebanyak 52.439 orang, sesuai dengan pertambahan jumlah pasien baru setiap harinya, maka jumlah dan ketebalan berkas rekam medis akan bertambah pula sehingga akan berpengaruh kepada kebutuhan rak penyimpanan berkas rekam medis.

\section{Rata-Rata Ketebalan Berkas Rekam Medis}

Ketebalan berkas rekam medis akan terus bertambah setiap harinya seiring 
dengan bertambahnya jumlah pasien yang berobat ke rumah sakit. Semakin banyak pasien baru yang datang berobat ke rumah sakit maka semakin bertambah pula jumlah berkas rekam medis di dalam rak penyimpanan.

Sesuai dengan hasil penelitian di Rumah Sakit Umum Madani Medan, ukuran ketebalan berkas rekam medis yang berjumlah 100 berkas adalah 43,2 cm. Dengan rata-rata ukuran untuk satu berkas rekam medis adalah $0,4 \mathrm{~cm}$.

Dengan rata-rata ketebalan berkas rekam medis $0,4 \mathrm{~cm}$, sehingga penambahan berkas rekam medis akan mempengaruhi rak penyimpanan, sebab setiap hari pasien terus bertambah maka jumlah dan ketebalan berkas rekam medis akan bertambah sesuai dengan jumlah pasien yang datang berobat ke Rumah Sakit Umum Madani Medan.

\section{Ukuran Rak Penyimpanan Rekam Medis}

Dalam menyimpan berkas rekam medis harus diperkirakan panjang pengarsipan yang diperlukan untuk dapat menyimpan berkas rekam medis dengan rapi dan teratur dalam jangka waktu tertentu.

Di Rumah Sakit Umum Madani Medan terdapat 7 (tujuh) unit rak dengan jumlah lebar keseluruhan rak adalah $\pm 10964 \mathrm{~cm}$. Dimana dengan jumlah lebar keseluruhan rak ini dikatakan sempit untuk penyimpanan seluruh berkas dalam lima tahun. Karena rak penyimpanan rekam medis tidak bisa menampung semua berkas rekam medis, sehingga berkas rekam medis pasien tidak dapat tersusun secara sistematis pada rak penyimpanan.

\section{Kebutuhan Jumlah Rak Penyimpanan}

Menurut Sis Wuryanto (2003) untuk menghitung kebutuhan rak berkas rekam medis terlebih dahulu menentukan kebutuhan untuk menyimpan berapa tahun rekam medis, berapa jumlah berkas rekam medis ada di rak aktif, jadwal penyusutan sesuai peraturan yang ada, jumlah pasien keluar rawat inap dan jumlah pasien baru rawat jalan, ukuran tebal rekam medis, hitung jumlah panjang jajaran rekam medis dalam waktu penyimpanan yang diinginkan dengan cara mengalikan jumlah rekam medis dalam waktu penyimpanan yaang diinginkan dikalikan dengan tebal berkas, tentukan jenis rak yang akan dipakai, hitung kemampuan rak untuk menampung panjang jajaran berkas rekam medis, maka akan ditemukan jumlah rak yang dibutuhkan.

Berdasarkan perhitungan prediksi kebutuhan rak file tadi jika saat ini rumah sakit memiliki 7 rak file, maka rumah sakit perlu menyediakan 4 rak file lagi agar kebutuhan rak dapat tercukupi dan dapat menampung semua berkas rekam medis pasien secara sistematis dan tidak menyulitkan petugas dalam proses penyimpanan dan pencarian berkas rekam medis pasien. Penambahan rak juga hendaknya disesuaikan dengan luas ruang penyimpanan, agar rak yang dibutuhkan dapat tsertata secara teratur sebagaimana mestinya.

\section{KESIMPULAN}

1. Jumlah rak file yang ada saat ini berjumlah 7 rak file

2. Ukuran rata-rata ketebalan berkas rekam medis pasien rawat jalan adalah $0,4 \mathrm{~cm}$.

3. Ukuran rak penyimpanan berkas rekam medis di RSU Madani Medan 10964 $\mathrm{cm}$.

4. Di Rumah Sakit Madani Medan belum pernah melakukan penyusutan berkas rekam medis

\section{SARAN}

Jika saat ini rumah sakit memiliki 7 rak file, maka rumah sakit perlu menyediakan 4 rak file lagi agar kebutuhan rak dapat tercukupi dan dapat menampung semua berkas rekam medis pasien secara sistematis dan tidak menyulitkan petugas dalam proses penyimpanan dan pencarian berkas rekam medis pasien.

\section{DAFTAR PUSTAKA}

Andriani. (2009). Sistem Informasi Pendaftaran Pasien Rawat Jalan di Rumah Sakit dengan Menggunakan 
Komputer. Tugas Akhir. Universitas Sumatra Utara.

Departemen Kesehatan Republik Indonesia.

(2013). Peraturan Menteri Kesehatan Republik Indonesia No. 55 Tahun 2013 tentang Pekerjaan Perekam Medis. Jakarta: Departemen kesehatan republik indonesia.

Departemen Kesehatan Republik Indonesia. (2009). Undang-Undang Republik Indonesia No. 44 Tahun 2009 tentang Rumah Sakit. Jakarta: Departemen Kesehatan Republik Indonesia

Hatta, Gemala. (2008). Pedoman Manajemen Informasi Kesehatan di
Sarana Pelayanan Kesehatan. Jakarta: UI-Press.

Kementrian Kesehatan RI, 2003 No. 560/MENKES/SK/IV/2003 tentang Tarif Rumah Sakit.

Notoatmodjo, Soekidjo. (2010). Metodologi Penelitian Kesehatan. Jakarta: Rineka Cipta.

Rustiyanto, Ery. 2009. Etika Profesi Perekam Medis \& Informasi Kesehatan. Yogyakarta: Graha Ilmu.

Saryono. (2013). Metodologi Penelitian Kualitatif dan Kuantitatif dalam Bidang Kesehatan. Yogyakarta: Nuha Medika. Sudra. (2014). Statistik Rumah Sakit. Yogyakarta: Graha Ilmu. 